\title{
Research on the Influence of Badminton Micro-curriculum Course Development and Teaching in Application-oriented Universities
}

\author{
Hong-jun MA \\ Wuhan Bussiness University, Wuhan, Hubei, China
}

Keywords: Applied undergraduate micro-class badminton teaching.

\begin{abstract}
With the continuous development of Internet technology, information-based teaching has become an indispensable form in modern Chinese teaching. As a new product in the information age, micro-curriculum has become a way for students to conduct autonomous learning and teachers to improve classroom teaching efficiency with its advantages of high efficiency, convenience, and interconnection as the carrier of communication. Badminton, as an emerging sports program in colleges and universities in recent years, is deeply loved by students. It combines micro-teaching with badminton teaching in applied colleges, can change the traditional teaching mode of badminton, and can effectively solve traditional badminton in current undergraduate colleges. There are many teaching problems in teaching methods. This article analyzes the design, development and teaching effects of high school PE micro-education, provides effective basis for the design and development of college PE micro-courses, and improves teaching efficiency in a targeted way.
\end{abstract}

\section{Introduction}

With the rapid development of Internet technology, the education and teaching model has been constantly changing. In recent years, the emergence and development of new network-based interactive teaching models based on the form of micro-teaching have accelerated the transformation of traditional teaching models in universities. The training model of applied-type undergraduate colleges and traditional universities has undergone major changes, and the "local-oriented, industry-oriented, and enterprise-oriented training of talents" emphasizes the comprehensive cultivation of talents' knowledge, ability, and quality ${ }^{[1]}$. The curriculum is based on "application orientation" as the design concept, and technology application activities as the main line, integrating technical disciplines and technical practices. Therefore, the micro-curricular design of applied undergraduates should be based on the local, industry demand for talents as the standard, and application-type personnel training as the teaching activity model.

With the popularity of badminton, badminton courses have been unanimously welcomed by college students. As an application-oriented college badminton course, students are required to regulate their technical movements, and their techniques and tactics are flexible. Therefore, in the production of micro-courses, it is necessary to highlight technology as the main line, and combine practice with techniques and tactics. In order to improve the quality of badminton teaching, this article focuses on the analysis of the design, development, and impact of badminton teaching on badminton. At present, there are few such studies in colleges and universities. Therefore, there is an important practical significance for the design, development and teaching research of college badminton micro-courses.

\section{Design of Badminton Micro-class for Application Bachelor}

When designing the undergraduate microbiology course for application-type undergraduate badminton, it is necessary to pay attention to the following points: (1) only one teaching point should be designed for each micro-education course. The teaching point should focus on the key points, difficulties, and doubts that students often encounter when learning technical skills in badminton. Easy to mistake. (2) Each lesson is designed to be short and concise, teaching time is short, total teaching time is designed within 10 minutes, and teaching is completed within the student's attention span. ${ }^{[2]}(3)$ The structure of each micro lesson is complete. The teaching point 
design should be an independent and complete teaching content, not a slice or a fragment. The selected skills content is the core content of a complete technical movement, ensuring the integrity of the motor skills and the main movements. ${ }^{[3]}(4)$ In accordance with the laws governing the teaching of physical education, the design of badminton micro-classes should follow the special activities of human activities and the mastery of badminton techniques and skills. These special laws include the formation of motor skills, the physical and psychological development of students, and the adaptation and changes of human body functions. Designers must determine the teaching tasks, teaching priorities and teaching methods according to the special laws of sports. 5 The design of micro lessons should make learners feel comfortable. The badminton micro-curricular video layout is reasonable, the senses are comfortable, and the screen images are clear. Pay attention to the use of technology should be just right, do not abuse the technology too much to make the picture flashy, this will instead distract the attention of the students to the video screen rather than the content of the lesson itself.

\section{Badminton Micro Lessons Development}

The development process of badminton micro-curriculum: Select the theme $\rightarrow$ analysis of the situation $\rightarrow$ teaching design $\rightarrow$ making micro-class $\rightarrow$ evaluation.

\section{Selecting a Theme}

Whether micro-classes can be designed well or not, the choice of topics is the key first step in micro-class design. Therefore, when designing badminton micro-courses, we should carefully consider the choice of topics. A micro-curriculum is a theme, mainly for the specific problems in badminton teaching practice. In the selection of topics, we should pay attention to clear topics, clear propositions, and moderate sizes. We can choose the difficulties, key points, doubt points, knowledge points, technical points, and skill points that often appear in badminton theories or practical courses as topics.

\section{Academic Analysis}

After selecting the topics, we will then conduct a student analysis. First of all, we must analyze the learners of this badminton micro-curriculum. What are the groups of students in this lesson? What are the characteristics of learners? How are the learners' basics? What are the characteristics of the courses in this class? What are the goals? What is the content of this lesson? These are all clearly analyzed before we implement the teaching.

\section{Teaching Design}

Having clearly defined the characteristics of the learner and the curriculum, teaching objectives and learning content, we can carry out targeted design of the teaching implementation process. The difference between badminton micro-classes and micro-courses in other disciplines is not a simple one, but focus on grasping the intrinsic laws of badminton technology, accumulating students' sports experience and experiencing sports experience, and forming sports experience. Accumulation. Whether such teaching aims can be achieved not only has a significant connection with badminton teaching philosophy, but also has a direct relationship with specific teaching measures and practices. ${ }^{[4]}$ In the implementation of teaching design to choose the appropriate teaching form, the main teaching methods of badminton micro-courses are scene-style, inquiry-style, explanation-type demonstration, demonstration-style, etc., we must choose according to the type of curriculum, teaching content, learners' characteristics teaching form. 


\section{Problems that should be Paid Attention to in the Teaching of Badminton Micro-class Production}

\section{Play a Complete Technical Movement in a Micro-course to Understand the Underlying Technology}

Badminton teaching not only enables students to hit the ball in the match, but also regulates their movements. The premise of standardizing the action is to allow students to fully understand the relevant basic technical movements, and micro-course teaching can be excellent through multimedia. The athlete's movements in the process of playing badminton are presented to the students for viewing, allowing the students to have a clear and comprehensive understanding of the badminton skills, and then through the video line, students can learn without using a long time of practice. The rhythm of the ball and the way to hit the ball.

\section{Detailed Video Tutorials for Playing Video in Slow Motion}

The sport of badminton emphasizes the speed of response and the flexibility of movement. Therefore, when teachers are teaching, they cannot allow the students to see clearly the teacher's standard actions. If the teacher teaches slow-motion demonstrations, it will generally fail to achieve the teaching effect and waste time. Therefore, the use of badminton The micro-course teaching will play the new technology first at normal speed, and then play in slow motion for the students' incomprehensible movements, so that the students can fully understand the essentials and strengthen their memory of badminton skills. For example, when teaching basic badminton teaching, a teacher may search for a video of a teaching service on the Internet. After playing the video for two times, students may try their own experiments. If they still cannot understand the action in practice, they will watch the teaching video again. ${ }^{5]}$ Through the combination of practice and video viewing, students can grasp the essentials of serving more quickly.

\section{Micro-courses Improve the Performance of Video and Standard Video}

After students fully understand the essentials of action, teachers need students to do a lot of practice in the process of practice, so that they can cultivate the feeling of playing badminton and the accurate judgment of the ball. These methods all need to be achieved through repeated exercises. Therefore, during the students' practice, the teacher can record the students' practice movements, let the students watch it and find their own deficiencies. After comparing the standard movements, Making reasonable assessments and resolving measures and correcting them not only failed to improve but also improved their learning ability. At the same time as the video teaching, we also need to use pictures to improve the effectiveness of teaching. Teachers can use the pictures to display more intuitively when explaining the technical movements. They can be combined with video teaching and use various aspects such as front, side, and back. The show made students aware of their deficiencies and find their own problems in order to correct them.

\section{Use of Playing Video to Inspire Students' Interest in Micro-course Teaching}

The reason why students like badminton is that they are interested in it. However, many students lose interest in badminton learning during repeated boring exercises. Therefore, teachers can interweave some wonderful game videos in the process of teaching. The students are given an effective impact, which in turn increases their interest in badminton and increases their motivation for learning. The teaching of micro-course not only plays an auxiliary role in badminton teaching, but also translates oral abstract speech into intuitive visual impact. It is more persuasive to students and the interaction between teachers and students can be more smooth. The study of badminton is not only a technical point, but also related tactics and rules students must understand. Teachers should combine these theories with multi-media teaching to enhance the students' knowledge of badminton from both visual and auditory perspectives. The memory. The video of the competition not only inspires students' interest, but also enables students to recognize the importance of tactics in the interesting video. The teacher will explain it from the side and guide the students to use flexibly in future competitions. Teachers can also organize relevant badminton competitions, record 
the students' competitions, and allow students to observe the deficiencies in their tactical use or the irregularities of their movements during playback. This is also a favorable combination of video feedback and badminton teaching. It can greatly enhance the quality of badminton teaching and allow students to avoid erroneous actions during practice ${ }^{[6]}$.

The badminton micro-curriculum has a profound impact on badminton teaching in applied undergraduate colleges and universities. It not only combines the theory and practice of badminton teaching, but also integrates the two, reveals the charm of badminton, and enables students to learn. The quicker grasp of the characteristics and laws of badminton sports is consistent with the teaching objectives and educational characteristics of application-oriented colleges and universities. In modern education, the use of micro lessons is becoming more and more extensive. It is no exception in badminton teaching in universities. This optimized combination has effectively solved the problems encountered by teachers in teaching and improved the quality of teaching. Fully reflects the idea of modern teaching, with innovative significance.

\section{Reference}

[1] Huijian Dai.Research on the Design, Development and Application of Sports Microteaching in Colleges and Universities, [J].Sport World, 2017(5)165-166

[2] Dachao Zhang. Development and Application of Multimedia CAI Courseware for Sports Technical Course Teaching Research [J].Journal of Beijing University of Physical Education, 2002(4).

[3] Xiuchang Zhang. Research on the college sports micro-courses in the Internet age [J]. Journal of Hunan Institute of Science and Technology, 2015(10). 178 - 180.

[4] Hao Sun. "Technology and Fitness" combination of micro-teaching design strategy [J]. Modern Education, 2015 (24). 46 - 47.

[5] Wanhui Liu. Micro-class development and production technology [M]. Beijing: Higher Education Press, 2015.

[6] Shangshang Liu, Influence of Badminton Micro-course on Badminton Teaching, [J] Teaching method, communication, talent, (2016)28-0098-01. 